\title{
The comparison of violence, and the relationship with childhood trauma in Turkish men with alcohol, opiate, and synthetic cannabinoid use disorder
}

This article was published in the following Dove Press journal:

Neuropsychiatric Disease and Treatment

\author{
Mine Ergelen' \\ Murat Yalçın² \\ Rabia Bilici \\ 'Practise and Research Center for \\ Fight Againist Addiction, University of \\ Health Sciences, ${ }^{2}$ The Psychotheraphy \\ Center, Erenköy Training and \\ Research Hospital for Psychiatry and \\ Neurology, Istanbul, Turkey
}

Objective: The objectives of this study are, first, to explore the prevalence of lifetime violent and criminal behaviors among alcohol, opioid, and synthetic cannabinoid (SC) users in the treatment program; second, to examine and compare sociodemographic characteristics, childhood traumatic experiences, and impulsivity of these groups.

Patients and method: This cross-sectional cohort study includes 110 male patients who received inpatient treatment in AMATEM (Alcohol and Substance Addiction Treatment Center) Clinic of Erenköy Training and Research Hospital for Psychiatry and Neurology between October 2014 and May 2015, diagnosed with alcohol, opioid, SC use disorder. The patients who were included in the study were given Data Collection Form, APIsoft (Addiction Profile Index), Childhood Trauma Questionnaire (CTQ-28), and Barratt Impulsiveness Scale (BIS-11). Statistical analysis was performed with SPSS 15.0 statistic software package.

Results: We found that resorting to verbal and physical violence was more frequent in SC group in comparison with alcohol and opiate groups (for verbal violence $88.5 \%, 60 \%, 70 \%$; $P=0.02$; for physical violence $(82 \%, 40 \%, 60 \% ; P=0.001)$. Criminal involvement was also higher for SC users than alcohol and opioid users $(94 \%, 85 \%, 68.5 \% ; P=0.01)$. The average CTQ-28 scores for SC group $(P=0.017)$ were high whereas there was no difference in the average BIS-11 scores $(P=0.073)$ between groups. There was no difference between the groups in terms of severity of addiction $(P=0.2)$. Our study ascertained that the patients exhibited mild and moderate addiction.

Conclusion: Although creating a treatment for addiction, we think that a holistic treatment that will take into consideration the used substance and the individual's childhood traumatic events along with his/her impulsive and aggressive behaviors could make a significant contribution to the prevention of the patient's possible violent and criminal behaviors in the future.

Keywords: addiction, drug use, violence, crime, childhood trauma, impulsivity

\section{Introduction}

Addiction has become an important problem across the world in recent years. In addition to leading to comorbid medical conditions and difficulties in the social domain, it has also brought about issues related to violence, crime, and law. The definition of violence varies among different studies; some authors defined violence as the total of the individual or collective actions that cause bodily or psychic damage on individuals by exerting force or oppression, ${ }^{1}$ whereas some other studies have examined interpersonal violence as in our study. ${ }^{2,3}$ WHO defined interpersonal violence as using force such as verbally, sexually, or physically that can occur either between family members, intimates, acquaintances, or strangers. ${ }^{4,5}$
University of Health Sciences Erenköy

Training and Research Hospital for Psychiatry and Neurology, 29 Sinan Ercan Caddesi, Erenkoy/Kadikoy, Istanbul 34736, Turkey

Tel +90 5354498245

Email mine.ergelen@gmail.com 
In the last few decades, the relationship between substance abuse and violent and criminal behavior has been addressed more frequently., ${ }^{2,6-8}$ Recurrent violent behavior has been found to be associated with young age, male sex, low socioeconomic level, low level of education, antisocial personality traits, alcohol-substance use, ${ }^{9}$ and impulsivity. ${ }^{10}$

The available data suggest that alcohol use is a significant risk factor for aggression and violent behavior ${ }^{11-13}$ and individuals who are inclined to aggression show more aggressive behaviors under the influence of alcohol when compared to the healthy individuals. ${ }^{14}$ In a study, conducted in our country to investigate the relationship between violence and substance use disorder in patients with bipolar disorder. The results of the study showed that the rate of lifetime substance use disorder was 59\%, and the most commonly abused substances were cannabis and alcohol, followed by synthetic cannabinoids (SCs). Individuals abusing any substance were more likely to have a criminal record and history of incarceration than other patients. ${ }^{15} \mathrm{SCs}$, composing a large group of the novel psychoactive substances, have unpredictable psychoactive effects due to variability of ingredients. ${ }^{16}$ It is argued that SCs increase violent behavior ${ }^{17}$ since they do not contain substances such as "Cannabidiol" and "Cannabivarin" that exist in cannabis and have a neuroprotective and antioxidant effect. ${ }^{18}$ A study reported that students who had ever used SCs, compared with those who had only experimented with cannabis, were more likely to have engaged in physical and upon another individual, injuring someone with a weapon on school property, physical fights, and carrying a weapon. ${ }^{19}$ However, it is unclear whether use of SCs leads to aggression and violent behavior or if aggressive tendencies of youths make them more prone to experiment with SCs. ${ }^{20}$

Clinical studies have investigated addiction in subjects who have violent behavior. In a study conducted in India on domestic violence with 267 participants, it was found out that $55 \%$ of the participants were subjected to violence by their spouses, and $63.19 \%$ of the participants who resorted to violence had alcohol use disorder, and $42.33 \%$ of them had opioid use disorder. ${ }^{21}$ There are some other studies that analyze the relationship from the opposite perspective. In a study advanced in Spain, 39\% of patients had experienced problems related to violence. ${ }^{2}$ The prevalence of interpersonal violence perpetration was found higher among substance addicted men than general population. ${ }^{22}$

Traumatic events experienced in the early periods of life are known to cause interpersonal problems, anxiety, and depression during adolescence and adulthood, and these traumatic events also pose a risk for substance abuse and produce a propensity for violence. ${ }^{23}$ In previous studies, substance abuse has been found to be associated with being subjected to physical violence, being involved in various violent behaviors, and committing a crime..$^{24,25}$

According to some studies conducted in other countries such as China, addiction is both a risk factor and a consequence of child abuse and abused children can show maladaptive drinking patterns in adolescence. It is found that males who were frequently beaten as children were significantly more likely to report being a binge drinker in adulthood than males who had never been beaten. ${ }^{26}$ Maltreatment of parents was significantly associated with higher prevalence of substance use. ${ }^{27}$ Addiction is not only associated with violence against children but also a risk for child for developing dependence in adulthood. ${ }^{26-28}$ A self-report survey, conducted among 12-18-year-old adolescents in Czech Republic, Russia, and USA found that in all three countries both substance use and problem behavior associated with addiction increased similarly along with severity of violence exposure and substance use increases along with the degree of violence exposure. ${ }^{29}$

Impulsivity could be described as a risk-bearing, common personality trait that frequently leads to undesired outcomes, and embarrassing situations; it involves acting suddenly to satisfy a desire. ${ }^{30,31}$ Impulsivity encapsulates behaviors such as weakness in planning one's actions, seeking excitement, failure in self-regulation, reduced control, and increased expectation for rewards. ${ }^{32-34}$ These manifestations of impulsivity could also be observed in addiction, committing violent crimes, personality disorders, and other psychiatric disorders. ${ }^{32,34}$ Besides, childhood abuse or neglect in alcohol and substance addicts could be considered to be related to impulsivity and aggression witnessed in this patient group. ${ }^{24,35,36}$ Impulsivity, aggression, and violence are not unidimensional; hence, it is difficult to identify their relationship. Studies also indicated that the structure of aggression and impulsivity differed dimensionally depending on addiction that could show different psychopharmacological properties and behavioral functions. ${ }^{37,38}$

When we examined the literature, we observed studies that investigate and compare alcohol, opioid, and other substances. In this study, we wanted to include users of SC, alcohol, and opioid, commonly abused substances in Turkey. The aims of this study are, first, to explore the prevalence of lifetime violent and criminal behaviors among alcohol, opioid, and SC users in the treatment program; second, to examine and compare sociodemographic characteristics, childhood traumatic experiences, and impulsivity of these groups. To our knowledge, this is the first study to investigate and 
compare SC users with these groups in the way of factors mentioned above.

\section{Patients and method Patients selection}

This cross-sectional cohort study includes 110 male patients who received inpatient treatment in AMATEM Clinic of Erenköy Training and Research Hospital for Psychiatry and Neurology between October 2014 and May 2015. All of these patients who applied for outpatient clinic of AMATEM voluntarily were diagnosed with alcohol, opioid, SC use disorder by psychiatrists and referred to inpatient treatment. Almost all of the patients admitted to inpatient ward were males. The patients were included to the study after completing their detoxification process. The inclusion criteria for the patients to be included in the study were as follows: to be diagnosed with alcohol, SC, or opioid use disorder by DSM-5, to be in treatment at AMATEM and having completed detoxification, and regression of the acute substance withdrawal symptoms indicated by the clinical follow-ups. The exclusion criteria were as having a cognitive disorder that may affect the interview and assessment, to be younger than 18 and older than 65 years of age, having a neurological or a general medical condition that may have an effect on the psychiatric chart, polysubstance use, and to be diagnosed with schizophrenia or with another psychotic disorder. We excluded the polysubstance users in order to examine substance-specific properties and to achieve homogeneity of the study sample. One hundred forty-four male patients were included in the study; however, a total of 54 patients were excluded from the study on the grounds that 32 of these patients used polysubstance; four of the patients had a psychotic disorder due to substance abuse; five of the patients had additional diagnoses for mood disorder, and 13 patients were released from the hospital before the completion of their detoxification process. Only male patients were included to provide homogeneity and due to the fact that there was no inpatient female SC addicts. The sample was representative of male substance users in the general population with regard to age distribution and level of addiction. After having been informed about the study, the patients who met the above-mentioned inclusion criteria were included in the study. Patients, who were diagnosed by at least two psychiatrists with alcohol, opioid, and SC use disorder by DSM-5 criteria, signed a consent form to indicate that their participation in the study was voluntary. The ethical approval for the study was obtained from Erenköy Training and Research Hospital for Psychiatry and Neurology Ethical Committee. The patients who participated in the study were given Patient Questionnaire Form, Addiction Profile Index (APIsoft), Childhood Trauma Questionnaire (CTQ), and Barratt Impulsiveness Scale (BIS).

\section{Methods}

\section{Patient questionnaire form}

It has been developed by the researchers for this study. This form includes information regarding patients' age, sex, marital status, employment status, the people they live with, history of violent behavior, legal history (the number of crimes committed, the type of crime, its severity, previous incarceration, use of alcohol, opioid, and SC while committing the crime, state of withdrawal, or being under the influence of substance). The types of crimes committed by the patients with a criminal history are classified as mildmoderate, severe-very severe violent crimes, and nonviolent crimes. "Mild-moderate violent crimes" include threat, insult, possession of unregistered firearm, mugging, aggressive intoxication, causing damage to property, assault without causing physical injury. "Severe-very severe violent crimes" include manslaughter, attempt to murder, injury, arson, and sexual offenses. Theft, distribution and selling of drugs, fraud, and public offenses are among "nonviolent crimes." Violence and addiction history of patients were the most important parameters for us, so we did not use a self-reported scale and made two interviews with patients to achieve more reliable and detailed information about patients' violence and criminal history. We prepared the questions about violence and criminal history by examining the existing scales.

\section{BIS version II (BIS-I I)}

BIS-11 is a self-report scale consisting of 30 items to measure impulsivity. ${ }^{39}$ The individuals are asked to choose the most appropriate option for them among "rarely/never", "Occasionally", "often", and "almost always/always". Factor analysis yielded three subfactors: 1) attentional impulsivity; 2) motor impulsivity; and 3) nonplanning impulsivity. Higher scores in the scale point to a high level of impulsivity. Validity and reliability study for the Turkish version of the scale has been carried out by Güleç et al. The internal consistency of the total scale was acceptable, with Cronbach's alpha being 0.80. Cronbach's alpha for the subscales ranged between 0.23 and 0.76 . Thus, the Turkish version of the BIS-11 (total score) could be accepted to have sufficient internal consistency reliability. ${ }^{40}$

\section{CTQ-28}

Developed by Bernstein et al in 1994, this questionnaire is a self-report scale consisting of Likert-type five-level items 
to offer a retrospective screening of children's and adolescents' trauma and neglect experiences. ${ }^{41}$ The questionnaire has five subscales, namely emotional abuse, physical abuse, sexual abuse, emotional neglect, and physical neglect. Items are scored on a five-point scale. The original version of the questionnaire consists of 70 items. In the validity and reliability study for the Turkish version of the scale's shorter version, which includes 28 items, cutoff was proposed to be above five points for sexual and physical abuse, above seven points for physical neglect and emotional abuse, over 12 points for emotional neglect, and over 35 points for the total score. ${ }^{42}$ The scale was adapted to Turkish. In the factor analysis conducted with the participation of CTQ-28 items, all types of trauma except physical neglect were found to be consistent with previously reported items. It was thought that physical neglect in this group of subjects had the least reported type of trauma affecting the findings and some corrections were made that clarified a small number of items that were understood to be influenced by language and culture. It is concluded that the Turkish version of CTQ-28 is valid and reliable. Cronbach's alpha value indicating the scale of the internal consistency for all groups was found to be $0.93 .{ }^{42}$

\section{APlsoft}

APIsoft is an internet-based scale that identifies the risk and needs of alcohol and substance users and contributes to the creation of an individualized treatment plan for patients. APIsoft is the online application of API. APIsoft includes a self-report form and scale. The individual with an addiction to alcohol and substance fills out this interview form on the computer. When the patient fills out the form, the computer reveals the information regarding the risk and needs of the patient by way of APIsoft, and a treatment plan is prepared accordingly. Since the questions included in APIsoft are asked out lout in the system, these questions also bear certain similarities with the forms that the interviewee fills out. In addition to the areas of questions included in API clinical form, APIsoft also poses questions for patients' alcoholsubstance use history, socioeconomic status, family relations, legal status, physical health, and strengths. Software includes and measures the following issues: Characteristics of addiction (type of alcohol/substance that is used, frequency and amount, age of onset), diagnostic criteria for addiction (the effect of the used alcohol/substance on one's life, motivation to quit, craving), addiction severity, treatment history, intravenous use of drugs, use of substitute treatment, mental state (depression, anxiety, suicide, psychological treatment history), personal traits (anger management problem, impulsivity, novelty seeking, lack of reliable behavior), familial and social relations (marital relations, parental relations), legal status (history of supervised release, previous incarceration), physical health (general evaluation, the drugs that are used, contagious diseases), socioeconomic level, level of education, place of residence, the people one lives with, working life, use of substance among friends, strengths (marital relations, parental relations, presence of nonusers among friends, consideration of alcohol/substance use as a problem, motivation to quit). The validity and reliability study of the scale has been conducted by Ögel et al. ${ }^{43,44}$ Cronbach's alpha coefficient for the whole questionnaire is 0.89 and for subscales of the questionnaire range from 0.63 to 0.86 .43

\section{Statistical assessment}

Statistical analysis was performed with SPSS 15.0 statistic software. Numeric data has been shown as an average \pm SD, and the categorical data have been shown as percentages. The differences among the categorical variables of the groups were assessed with the chi-squared test and, when necessary, the Fisher's exact test. Although comparing the numeric values among alcohol, opioid, and SC groups, one-way ANOVA was used, and $t$-test was performed for the independent sample. The post-hoc analyses of numeric variables have been carried out through Tukey's test. For all the statistical analyses, the $P$-value has been accepted to be significant for $<0.05$.

\section{Results}

The present study included 35 alcohol, 40 opioid, and 35 SC users. Among the groups, the patients with the alcohol use disorder were significantly older in comparison to patients with opioid and SC use disorder. As a result of the post-hoc analysis that was carried out to determine which group was responsible for the difference, we found a significant difference between alcohol and opioid addicts, and alcohol and SC addicts $(P<0.001 ; P<0.001)$. The rates of leading a solitary life, having a regular income, and the rate of being a college graduate were higher in the alcohol group. The rates for unemployment and being married showed a similar distribution across the groups (see Table 1).

The SC group showed significantly higher frequency of involvement in verbal and physical violence. The criminal history and the rate of crime after being addicted were higher in opioid and SC groups. While no significant difference was identified among the groups regarding incarceration and the 
Table I Comparison of demographic characteristics in alcohol, opioid, and SC groups

\begin{tabular}{|c|c|c|c|c|c|}
\hline & $\begin{array}{l}\text { Alcohol } \\
(n=35)\end{array}$ & $\begin{array}{l}\text { Opioid } \\
(n=40)\end{array}$ & $\begin{array}{l}\text { SC } \\
(n=35)\end{array}$ & $F / \chi^{2}$ & $P$-value \\
\hline Age, year \pm SD & $46.5 \pm 9$ & $26.5 \pm 6.7$ & $28.2 \pm 7.1$ & 70.08 & $0.000^{a}$ \\
\hline Married, n (\%) & $23(65.7)$ & $33(82.5)$ & $27(77.1)$ & 2.919 & 0.232 \\
\hline Leading a solitary life, $n(\%)$ & $13(37.1)$ & $2(5.0)$ & $3(8.0)$ & 16.369 & $0.00 I^{b}$ \\
\hline Unemployment, n (\%) & $12(34.3)$ & $16(40.0)$ & $10(28.6)$ & 1.08 & 0.583 \\
\hline Having a regular income, n (\%) & $24(68.6)$ & $20(50.0)$ & $9(25.7)$ & 12.957 & $0.002^{\mathrm{a}}$ \\
\hline Level of education, $n(\%)$ & & & & 17.291 & \\
\hline Elementary school & $8(22.8)$ & $5(12.5)$ & $8(22.8)$ & & $0.008^{a}$ \\
\hline Secondary school & $8(22.8)$ & $23(57.5)$ & $18(51.4)$ & & \\
\hline High school & $15(42.8)$ & $12(30)$ & $9(25.7)$ & & \\
\hline University & $4(11.4)$ & $0(0)$ & $0(0)$ & & \\
\hline
\end{tabular}

Notes: a'Significant for $P<0.05$. 'Fisher's exact test. Bold values indicate statistical significance between groups.

Abbreviation: SC, synthetic cannabinoid.

types of crime. Being under supervised release was higher for SC group (see Table 2).

The mean scores of the CTQ-28 and its physical abuse, emotional abuse, and emotional neglect subscales were higher in SC group. The cutoff scores were proposed to be above five points for sexual and physical abuse, above seven points for physical neglect and emotional abuse, over 12 points for emotional neglect, and over 35 points for the total score. All of the scores of all groups were above the cutoff values (see Table 3 ).

Attentional impulsivity scores for alcohol, opioid, and $\mathrm{SC}$ groups are $(17.2 \pm 6.2,17.2 \pm 4.4,18.8 \pm 3.7 ; P=0.294)$; the scores for motor impulsivity are $(22.2 \pm 5.5,23.9 \pm 7.4$, $24.7 \pm 5.6 ; P=0.249)$, and the scores for total impulsivity are $(67.3 \pm 14.1,69.7 \pm 14.3,74.7 \pm 12.1 ; P=0.073)$. The average scores for each group were similar. The average score for "nonplanning impulsivity" was found to be higher for SC group when compared with alcohol and opioid groups $(31.1 \pm 5.5,27.8,1 \pm 5.6,28.6 \pm 5.9 ; P=0.04)$. The post-hoc test was carried out to investigate which group was responsible for the difference. As a result, it was observed that the nonplanning impulsiveness was higher in SC users $(P=0.04)$ as against alcohol users. The total API scores demonstrating the addiction severity was found to be similar in each group (for alcohol, opioid, and SC groups, respectively $(2.3 \pm 0.37,2.37 \pm 0.24,2.4 \pm 0.25 ; P=0.2)$. Our study ascertained that the patients exhibited mild and moderate addiction.

In the alcohol group, scores for addiction severity, CTQ-28, and BIS-11 did not indicate significant difference between those that showed violent behavior and those that did not. Similarly, scores for addiction severity, CTQ-28, and BIS-11 did not reveal a significant difference between patients with a history of crime and patients with no history of crime (see Table 4). We found that $57.1 \%(n=20)$ of the patients who committed a crime in the alcohol group did so while under the influence of alcohol/substance. In the opioid group, addiction severity did not show any significant difference between patients who showed violent behavior and patients who did not; however, CTQ-28 and BIS-11 scores were significantly higher in the patient group that showed violent behavior. Addiction severity and BIS-11 scores in

Table 2 Comparison of violence and crime in alcohol, opioid, and SC groups

\begin{tabular}{|c|c|c|c|c|c|}
\hline & $\begin{array}{l}\text { Alcohol } \\
(n=35)\end{array}$ & $\begin{array}{l}\text { Opioid } \\
(n=40)\end{array}$ & $\begin{array}{l}S C \\
(n=35)\end{array}$ & $\chi^{2}$ & $P$-value \\
\hline Resorting to verbal violence, $\mathrm{n}(\%)$ & $21(60.0)$ & $28(70.0)$ & $3 I(88.5)$ & 7.438 & $0.02^{\mathrm{a}}$ \\
\hline Resorting to physical violence, $\mathrm{n}(\%)$ & $14(40.0)$ & $24(60.0)$ & $29(82.0)$ & 13.522 & $0.00 I^{a}$ \\
\hline Resorting to sexual violence, $\mathrm{n}(\%)$ & $\mathrm{I}(2.8)$ & I (2.5) & $2(5.7)$ & 0.639 & $0.72^{\mathrm{b}}$ \\
\hline Criminal history, n (\%) & $24(68.5)$ & $34(85.0)$ & $33(94.0)$ & 8.325 & $0.0 \mathrm{I}^{\mathrm{a}}$ \\
\hline Incarceration, n (\%) & $13(37.1)$ & $12(30.0)$ & $15(42.8)$ & 1.347 & 0.51 \\
\hline Mild-moderate violent crimes, $\mathrm{n}(\%)$ & $6(33.3)$ & $8(38.1)$ & $6(28.6)$ & 4.417 & 0.305 \\
\hline Severe-very severe violent crimes, n (\%) & $8(44.4)$ & $4(19.0)$ & $10(47.6)$ & 4.417 & $0.315^{b}$ \\
\hline Nonviolent crimes, n (\%) & $4(22.2)$ & $9(42.9)$ & $5(23.8)$ & 4.417 & $0.315^{b}$ \\
\hline Being under supervised release, $\mathrm{n}(\%)$ & $4(I I .4)$ & $27(67.5)$ & $3 I(88.5)$ & 42.144 & $0.000^{b}$ \\
\hline
\end{tabular}

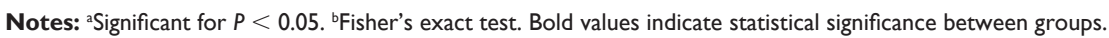

Abbreviation: SC, synthetic cannabinoid. 
Table 3 Comparison of groups' average scores for CTQ-28 and subscales

\begin{tabular}{|c|c|c|c|c|c|}
\hline & $\begin{array}{l}\text { Alcohol } \\
(n=35)\end{array}$ & $\begin{array}{l}\text { Opioid } \\
(n=40)\end{array}$ & $\begin{array}{l}\text { SC } \\
(n=35)\end{array}$ & $\boldsymbol{F}$ & $P$-value \\
\hline Physical abuse, avg \pm SD & $7.2 \pm 3.5$ & $6.8 \pm 2.9$ & $10.05 \pm 4.5$ & 8.228 & $0.000^{a}$ \\
\hline Physical neglect, avg $\pm \mathrm{SD}$ & $10.3 \pm 3.1$ & $8.9 \pm 3.09$ & $9.7 \pm 3.6$ & 1.675 & 0.19 \\
\hline Emotional abuse, avg $\pm S D$ & $9.3 \pm 3.5$ & $8.2 \pm 3.9$ & $10.5 \pm 4.1$ & 3.246 & $0.043^{a}$ \\
\hline Emotional neglect, avg \pm SD & $12.9 \pm 4.6$ & $12.02 \pm 4.6$ & $14.8 \pm 4.6$ & 3.333 & $0.039^{a}$ \\
\hline Sexual abuse, avg \pm SD & $5.7 \pm 2.2$ & $5.7 \pm 2.2$ & $6.2 \pm 2.3$ & 0.679 & 0.509 \\
\hline Total CTQ, avg \pm SD & $45.6 \pm 13.7$ & $41.7 \pm 13.9$ & $51.4 \pm 14.8$ & 4.224 & $0.017^{a}$ \\
\hline
\end{tabular}

Note: ${ }^{a}$ Significant for $P<0.05$. Bold values indicates statistical significance between groups.

Abbreviations: avg, average; CTQ, Childhood Trauma Questionnaire.

opioid-using group was significantly higher for patients with a criminal history.

When we examined the CTQ-28 scores of patients who committed crimes and those that did not, the $P$-value was liminal, 0.052. Considering that the traumatic experiences in childhood, especially sexual traumas, could not be expressed, and thereby kept secret, the difference was accepted as significant for the patient group with a criminal history (see Table 4). A total of $70 \%$ of the opioid-using group was under the influence of substance while committing a crime. No significant difference was detected among the violent and nonviolent patients in SC group in terms of addiction severity scores, CTQ-28, and BIS-11 scores. Addiction severity and BIS-11 scores did not reveal any significant difference between patients with a criminal history and those without a criminal history among SC users. CTQ-28 scores were significantly higher for criminal patients in SC group. In SC group, $74.3 \%$ of patients committed crimes while under the influence of the substance (see Table 4).

\section{Discussion}

When the three groups consisting of patients with alcohol, opioid, and SC use disorder were assessed in terms of their sociodemographic characteristics, such as age, leading a solitary life, and having a regular income; our results were found to be consistent with some other studies form our country. ${ }^{45,46,37}$

In our study, we observed that the history of resorting to verbal and physical violence was more frequent in patients with SC users then alcohol and opioid users. Among the studies examining the relationship between violence and substance abuse, opioid use was found to have less relation with violence as well as the alcohol was found to be highly related than the other substance uses. ${ }^{5,8,47}$ In this context, we can make an assumption that SCs, as drugs that were already reported to be in a relation with violence and aggressive behavior, ${ }^{19,20}$ should be considered as a potential cause of drug-related violence.

Various studies have shown that violence is related with young age, ${ }^{2}$ low level of education, unemployment,

Table 4 Comparison of patients with/without violent behavior and with/without a criminal history regarding API, CTQ, and BIS in the alcohol, opioid, and SC groups

\begin{tabular}{|c|c|c|c|c|c|c|c|}
\hline & & $\begin{array}{l}\text { Violent } \\
\text { behavior } \\
(+)\end{array}$ & $\begin{array}{l}\text { Violent } \\
\text { behavior } \\
(-)\end{array}$ & $P$-value & $\begin{array}{l}\text { Crime } \\
(+)\end{array}$ & $\begin{array}{l}\text { Crime } \\
(-)\end{array}$ & $P$-value \\
\hline \multirow[t]{4}{*}{ Alcohol group } & & $(n=2 I)$ & $(n=14)$ & & $(n=14)$ & $(n=2 I)$ & \\
\hline & $A P I$, avg $\pm S D$ & $2.3 \pm 0.4$ & $2.2 \pm 2.02$ & 0.960 & $2.3 \pm 0.3$ & $2.2 \pm 0.3$ & 0.880 \\
\hline & CTQ-28, avg \pm SD & $44.1 \pm 11.01$ & $47.8 \pm 17.2$ & 0.774 & $46.07 \pm 11.05$ & $45.3 \pm 15.4$ & 0.533 \\
\hline & BIS-II, avg \pm SD & $69.7 \pm 15.2$ & $63.7 \pm 12.1$ & 0.288 & $71.9 \pm 16.2$ & $64.2 \pm 12.2$ & 0.219 \\
\hline \multirow[t]{4}{*}{ Opioid group } & & $(n=26)$ & $(n=14)$ & & $(n=14)$ & $(n=26)$ & \\
\hline & $A P I$, avg $\pm S D$ & $2.4 \pm 0.2$ & $2.3 \pm 0.2$ & 0.109 & $2.4 \pm 0.2$ & $2.3 \pm 0.2$ & $0.049^{a}$ \\
\hline & CTQ-28, avg \pm SD & $46 \pm 15.2$ & $33.9 \pm 6.14$ & $0.005^{\mathrm{a}}$ & $48.3 \pm 17.9$ & $38.2 \pm 10$ & $0.052^{c}$ \\
\hline & BIS-II, avg \pm SD & $73.7 \pm 13.7$ & $62.3 \pm 12.7$ & $0.029^{a}$ & $79.6 \pm 12.7$ & $64.4 \pm 12.3$ & $0.002^{\mathrm{a}}$ \\
\hline \multirow[t]{4}{*}{ SC group } & & $(n=3 I)$ & $(n=4)$ & & $(n=17)$ & $(n=18)$ & \\
\hline & $A P I$, avg $\pm S D$ & $2.4 \pm 0.2$ & $2.5 \pm 0.2$ & 0.265 & $2.4 \pm 0.2$ & $2.4 \pm 0.2$ & 0.531 \\
\hline & CTQ-28, avg \pm SD & $51.9 \pm 15.7$ & $47.2 \pm 13.5$ & 0.64 & $59.1 \pm 15.3$ & $44.1 \pm 11.7$ & $0.007^{\mathrm{a}}$ \\
\hline & BIS-II, avg \pm SD & $74.5 \pm 12.6$ & $76.2 \pm 8.6$ & 0.717 & $74.7 \pm 12.7$ & $74.7 \pm 12.04$ & 0.987 \\
\hline
\end{tabular}

Notes: aSignificant for $P<0.05$; indicates data was at liminal value.

Abbreviations: avg, average; CTQ, Childhood Trauma Questionnaire; BIS, Barratt Impulsiveness Scale; API, Addiction Profile Index; SC, synthetic cannabinoid. 
and having a low income. ${ }^{21}$ We observed in our study that the average age, education level, and sociocultural status of the SC-using group was lower than others. We assumed that SC users, mostly consisting of disadvantaged population ${ }^{48}$ prefer SC since it is cheap and readily available. However, while we cannot ascertain the exact reasons for the high level of violent behavior in this group, we hypothesize the high level of violent behavior in this group is related with these factors described above.

We determined that the rate of criminal histories in patients using SC and opioid was higher in comparison with alcohol users. As we examined the literature, there are some studies indicating that having a criminal history is more prevalent in $\mathrm{SC}$ users ${ }^{17}$ and is lower among alcohol users, ${ }^{4-49}$ which are consistent with our findings. Concerning substance addicts, it was demonstrated that along with legal issues and incarceration, dangerous, and damaging behaviors were more common under the influence of the substance..$^{50}$ We observed that the rate of crime across opioid and SC groups was higher than the alcohol group after the addiction was developed. Previous studies have already indicated that the number of crimes committed during active addiction period has been seen more than the crimes committed during a nonaddictive period, and the addicts commit crimes, such as mugging, theft, prostitution, and certain other offenses to obtain the money they need to buy the substance. Concerning opioid and cocaine users, in particular, it has been observed that there is a significant correlation between the frequency of using a substance and committing crimes. ${ }^{6,51}$ In line with our findings, a study conducted by Ögel and Aksoy (2007) in Turkey, demonstrates that the use of alcohol and cannabis have generally been started to use before offending a crime while heroin has usually been used after one starts committing a crime..$^{52}$

When we assessed the patients by types of crimes committed, we could not identify a statistically significant difference across these three groups. Håkansson et al showed that alcohol was the preferred substance in violent crimes while people who committed nonviolent crimes used heroin. ${ }^{8}$ In another study conducted with imprisoned and convicted adolescents, it was observed that the most frequently used substance was tobacco and alcohol, and the least frequently used substance was heroin. ${ }^{52}$ Algül et al indicated that concerning violent crimes, the substance use disorder rates are significantly higher in comparison with nonviolent crimes. ${ }^{53}$ In a different study carried out in Norway, it was reported that among the individuals who committed crimes under the influence of a substance, SC was used more frequently than alcohol and other substance. ${ }^{54}$
Addiction severity is an essential criterion in choosing the treatment method to be applied. In individuals with a severe addiction, a more intense treatment procedure should be implemented. ${ }^{55}$ Individuals with a severe addiction show more violent behaviors. ${ }^{2}$ In our study, no significant difference was identified across the groups regarding addiction severity. It is known that addiction severity, impulsivity, and abuse-neglect histories are influential in determining the type of treatment and the continuance of that treatment. ${ }^{56}$ Considering that the individuals who resort to violence and commit crime respond less to the addiction treatment; ${ }^{2}$ we can hypothesize that the reason why the patients included in our study were found to have mild-moderate level of addiction could be related to the fact that we worked with a group of patients capable of continuing the treatment.

When the groups in our study were compared regarding their CTQ-28 scores, the total scale scores of all the groups for CTQ-28 were found to be higher than the scale's cutoff. We observed that the patients with SC use disorder had higher average scores for physical and emotional abuse and emotional neglect subscales. Their total average score was also higher than the patients with alcohol and opioid use disorder. In a study conducted with convicted alcohol and substance addicts, physical abuse was found to be high in alcohol addicts while sexual abuse was found to be high in substance users. ${ }^{57}$ In another study conducted in the USA, it was observed that children who were sexually abused during their childhood used cocaine and cannabis, whereas male individuals who were subjected to physical and emotional abuse used cocaine and heroin. Being subjected to multiple traumas during childhood was found to be associated with alcohol use.$^{58}$ It is thought that alcohol and substance abuse is a method to deal with the mental troubles that the individuals who were subjected to and suffered from traumatic experiences during their childhood. It has been argued that severe or multiple traumatic experiences, in particular, may lead to risky behaviors such as using illegal substances. ${ }^{57} \mathrm{We}$ found values above cutoff scores for CTQ-28 for each group. Even though it is not possible to establish a direct causal link, we can hypothesize that $\mathrm{SC}$ was the preferred substance for the group in which CTQ-28 scores were higher due to the fact that this substance is readily available, forms a "chemical dissociation" state through its potent psychoactive effects, ${ }^{59}$ and so the individual tries to alleviate his/her negative feelings through this way.

It has been claimed that impulsive individuals are caught up more in negative feelings such as anger, anxiety, and restlessness, and they try to alleviate these feelings by way of alcohol and substance abuse. ${ }^{60}$ We did not identify a 
statistically significant difference across the groups regarding attentional and motor impulsivity, and total BIS-11 scores. It is known that individuals with impulsive personality traits have a high level of illegal substance abuse. ${ }^{61}$ There are other studies indicating that nonplanning impulsivity is higher in SC users ${ }^{62}$ as in our study. Even though there are studies demonstrating that the total score of BIS-11 for alcohol and opioid addicts is similar, ${ }^{37}$ some other studies indicate that heroin addicts are more impulsive than alcohol addicts. ${ }^{63}$ Since the issue of whether the alcohol or substance addicts use substance due to impulsivity or substance abuse increase impulsivity is not a clear-cut question, ${ }^{64}$ the accompanying psychopathologies and personal traits of the individual should be investigated as well. The areas for addiction and decisionmaking are connected to each other in the brain, and these areas mature in adolescence; therefore, there are also specific claims that alcohol and substance use increase impulsivity especially in adolescence. ${ }^{65}$ Given that substance abuse at an early age has a negative impact on impulse development, ${ }^{66}$ we think that the reason why impulsivity is high in SC group may be related to the fact that the average age of the SC group is low. Considering that violent behavior and criminal history are also high in SC group, it is possible that impulsivity in this group might be related to some other underlying psychopathologies.

Hammersley et al showed that severe opioid addicts commit more crimes when compared to moderate level addicts, ${ }^{67}$ as consistent with our results. Concerning patients who showed violent behavior and patients who did not, no difference was found regarding addiction severity in the SC group. In the same vein, addiction severity was similar for criminal and noncriminal patients. In literatures, we did not encounter a study that investigates this issue. Considering that addicted patients who resort to violence and commit crimes respond less to treatment efforts, ${ }^{2}$ we concur with the authors who have previously reported that for these patients a structured and eclectic treatment that assesses the patient's early traumatic experiences and impulsive behaviors should be planned. ${ }^{6}$

\section{Limitations}

The fact that we were only able to include patients receiving inpatient treatment to our study due to our circumstances prevented us from acquiring data regarding outpatients. The criterion stating that the patients should complete their detoxification process so that they could adapt to the interview and fill out the scales, and the criterion that excludes polysubstance users since we wanted to address the differences among the groups, led to a limitation regarding acquiring data from these patient groups.

The inclusion of male patients who received inpatient treatment and were diagnosed with alcohol, opioid, and SC use disorder; the relative limitedness of the number of patients in the groups; the fact that the information regarding patients' violent behavior and crimes were filled out on by self-report; and the use of self-report scales form the other limitations of our study.

\section{Conclusion}

We have found that violent and criminal behaviors were related to childhood traumatic experiences and impulsivity, especially in the opioid-using group. We observed that the propensity to violence and impulsive behaviors were significantly higher in SC users in comparison with alcohol- and opioid-using patients. Considering that the current responses are still quite low in addiction treatment, our findings show that in preparing treatment for addiction patients who show violent and criminal behavior, it might be essential to take into consideration the individuals' childhood traumatic experiences, their impulsive and aggressive behaviors, and their relationship with the preferred substance. In this way, we think that it will be possible to plan a structured, individualized, and target-oriented holistic treatment and to attain more effective treatment conditions.

\section{Disclosure}

The authors report no conflicts of interest in this work.

\section{References}

1. Boşgelmez Ş, Aker T. Şiddet, Ruhsal Travma ve Sonuçları. Turkiye Klin J Psychiatry-Special Top. 2011;4:26-31.

2. Fernández-Montalvo J, López-Goñi JJ, Arteaga A. Violent behaviors in drug addiction: differential profiles of drug-addicted patients with and without violence problems. J Interpers Violence. 2012;27(1): 142-157.

3. Flórez G. Psychopathy, addictions, interpersonal violence and antisocial behavior, a mixed relationship. Adicciones. 2016;28(2):65-70.

4. Waters H, Hyder AA, Rajkotia Y, Basu S, Rehwinkel JA, Butchart A, World Health Organization. The economic dimensions of interpersonal violence; 2004:1-56.

5. Montesanti SR, Thurston WE. Mapping the role of structural and interpersonal violence in the lives of women: implications for public health interventions and policy. BMC Womens Health. 2015;15:100.

6. Nurco DN, Shaffer JW, Ball JC, Kinlock TW. Trends in the commission of crime among narcotic addicts over successive periods of addiction and nonaddiction. Am J Drug Alcohol Abuse. 1984;10(4):481-489.

7. Darke S, Torok M, Kaye S, Ross J, Mcketin R. Comparative rates of violent crime among regular methamphetamine and opioid users: offending and victimization. Addiction. 2010;105(5):916-919.

8. Håkansson A, Jesionowska V. Associations between substance use and type of crime in prisoners with substance use problems - a focus on violence and fatal violence. Subst Abuse Rehabil. 2018;9:1-9.

9. Harris GT, Rice ME, Sc B. Risk appraisal and management of violent behavior. Psychiatr Serv. 1997;48(9):1168-1176. 
10. Wong SCP, Gordon A. The validity and reliability of the Violence Risk Scale: a treatment-friendly violence risk assessment tool. Psychol Public Policy Law. 2006;12(3):279-309.

11. Bachman R. Violence against women: A national crime victimization survey report. Washington, DC: US Department of Justice, Office of Justice Programs, Bureau of Justice Statistics; 1994. Available from: https://www.ncjrs.gov/pdffiles1/digitization/145325ncjrs.pdf. Accessed May 8, 2018.

12. López-Goñi JJ, Fernández-Montalvo J, Menéndez JC, et al. Group and individual change in the treatment of drug addictions: a follow-up study in therapeutic communities. Span J Psychol. 2010;13(2):906-913.

13. López-Goñi JJ, Fernández-Montalvo J, Arteaga A. Predictive validity of the EuropASI: clinical diagnosis or composite scoring? J Subst Abuse Treat. 2012;42(4):392-399.

14. Bailey DS, Taylor SP. Effects of alcohol and drinking experience on human physical aggression. Personal Soc Psychol Bull. 1994;20(4):439-444.

15. Alnıak I, Erkıran M, Mutlu E. Substance use is a risk factor for violent behavior in male patients with bipolar disorder. J Affect Disord. 2016; 193:89-93.

16. Vandrey R, Dunn KE, Fry JA, Girling ER. A survey study to characterize use of spice products synthetic cannabinoids. Drug Alcohol Depend. 2012;120(1-3):238-241.

17. Shafi A, Gallagher P, Stewart N, Martinotti G, Corazza O. The risk of violence associated with novel psychoactive substance misuse in patients presenting to acute mental health services. Hum Psychopharmacol. 2017;32(3):e2606.

18. Iseger TA, Bossong MG. A systematic review of the antipsychotic properties of cannabidiol in humans. Schizophr Res. 2015;162(1-3):153-161.

19. Clayton HB, Lowry R, Ashley C, Wolkin A, Grant AM. Health risk behaviors with synthetic cannabinoids versus marijuana. Pediatrics. 2017;139(4):e20162675.

20. Kolla NJ, Mishra A. The endocannabinoid system, aggression, and the violence of synthetic cannabinoid use, borderline personality disorder, antisocial personality disorder, and other psychiatric disorders Front Behav Neurosci. 2018;12:41.

21. Subodh NB, Grover S, Grewal M, et al. Interpersonal violence against wives by substance dependent men. Drug Alcohol Depend. 2014; 138:124-129.

22. Gilchrist G, Radcliffe P, Noto AR, D'Oliveira AF. The prevalence and factors associated with ever perpetrating intimate partner violence by men receiving substance use treatment in Brazil and England: a crosscultural comparison. Drug Alcohol Rev. 2017;36(1):34-51.

23. Şar V. Kötüye kullanım ve ihmalle ilişkili sorunlar. Temel Psikiyatri. 1997:823-834.

24. Cuomo C, Sarchiapone M, Giannantonio MD, Mancini M, Roy A. Aggression, impulsivity, personality traits, and childhood trauma of prisoners with substance abuse and addiction. Am J Drug Alcohol Abuse. 2008;34(3):339-345.

25. Altuner D, Engin N, Gürer C, Akyay İ, Akgül A. Madde Kullanımı ve Suç İlişkisi: Kesitsel Bir Araştırma. Tıp Araşırmaları Derg. 2009;7(2):87-94.

26. Kim JH, Leung MC, Yip BH, Su X, Griffiths SM. Exploring crossgenerational adult drinking patterns and physical child maltreatment: a study of Hong Kong adults. Public Health. 2017;144:143-146.

27. Lau JT, Kim JH, Tsui HY, Cheung A, Lau M, Yu A. The relationship between physical maltreatment and substance use among adolescents: a survey of 95,788 adolescents in Hong Kong. J Adolesc Health. 2005; 37(2):110-119.

28. Tremblay RE, Nagin DS, Séguin JR, et al. Physical aggression during early childhood: trajectories and predictors. Pediatrics. 2004;114(1):e43-e50.

29. Löfving-Gupta S, Willebrand M, Koposov R, et al. Community violence exposure and substance use: cross-cultural and gender perspectives. Eur Child Adolesc Psychiatry. 2018;27(4):493-500.

30. Kreek MJ, Nielsen DA, Butelman ER, Laforge KS. Genetic influences on impulsivity, risk taking, stress responsivity and vulnerability to drug abuse and addiction. Nat Neurosci. 2005;8(11):1450-1457.

31. Ozdemir P, Selvi Y, Aydin A. Impulsivity and its treatment. Psikiyatr Guncel Yaklasimlar - Curr Approaches Psychiatry. 2012;4:293.
32. Evenden J. Impulsivity: a discussion of clinical and experimental findings. J Psychopharmacol. 1999;13(2):180-192.

33. Bevilacqua L, Doly S, Kaprio J, et al. A population-specific HTR2B stop codon predisposes to severe impulsivity. Nature. 2010;468(7327): 1061-1066.

34. Singh PK, Rao VR. Explaining suicide attempt with personality traits of aggression and impulsivity in a high risk tribal population of India. PLoS One. 2018;13:1-13.

35. Santa Mina EE, Gallop RM, Ruth M. Childhood sexual and physical abuse and adult self-harm and suicidal behaviour: a literature review. Can J Psychiatry. 1998;43(8):793-800.

36. Kısa C, Yıldırım SG, Göka E. Ataklık ve Ruhsal Bozukluklar. Türk Psikiyatr Derg. 2005;16:46-54.

37. Bozkurt M, Evren C, Yilmaz A, Can Y, Cetingok S. Aggression and impulsivity in different groups of alcohol and heroin dependent inpatient men. Klin Psikofarmakol Bülteni-Bulletin Clin Psychopharmacol. 2013;23:335-344.

38. Clark L, Robbins TW, Ersche KD, Sahakian BJ. Reflection impulsivity in current and former substance users. Biol Psychiatry. 2006; 60(5):515-522.

39. Patton JH, Stanford MS, Barratt ES. Factor structure of the Barratt impulsiveness scale. J Clin Psychol. 1995;51(6):768-774.

40. Güleç H, Tamam L, Yazıcı M, Stanford MS. Psychometric properties of the Turkish version of the Barratt Impulsiveness Scale-11. Bull Clin Psychopharmacol. 2008;18:251-258.

41. Bernstein DP, Fink L, Handelsman L, Foote J, Lovejoy M, Wenzel K, Sapareto E, Ruggiero J. Initial reliability and validity of a new retrospective measure of child abuse and neglect. Am J Psychiatry. 1994; 151(8):1132.

42. Şar V, Öztürk E, Ikikardeş E. Çocukluk çaği\{dotless\} ruhsal travma ölçeğinin Türkçe uyarlamasi\{dotless \}ni\{dotless \}n geçerlilik ve güvenilirliği. Turkiye Klin J Med Sci. 2012;32:1054-1063.

43. Ögel K, Evren C, Karadağ F, Gürol Tamar D. Bağımlılık Profil İndeksi'nin (BAPİ) Geliştirilmesi, Geçerlik ve Güvenilirliği. Türk Psikiyatr Derg. 2012;23:264-273.

44. Ögel K, Koç C, Başabak AZ. İşmen, Ebru Mebrure Görücü, S. Development of addiction profile index (Bapi) clinical form: reliability and validity study. Bağımlılık Derg. 2015;16:57-69.

45. Bulut M, Cansel N, Selek S, Yumru M. Gaziantep üniversitesi alkol ve madde hastalarin sosyodemografik özellikleri [Sociodemographic characteristics of patients applied to Substance Usage Disorders Unit of Gaziantep University]. Bağlmlılık Dergisl. 2006;7: 65-70.

46. Evren C. Madde Kullananların özellikleri: 2000 Yılına ait AMATEM'e yatan hasta verilerinin incelenmesi. Düşünen Adam. 2001;14:142-149.

47. Arteaga A, Fernández-Montalvo J, López-Goñi JJ. Prevalence and differential profile of patients with drug addiction problems who commit intimate partner violence. Am J Addict. 2015;24(8):756-764.

48. Joseph AM, Manseau MW, Lalane M, Rajparia A, Lewis CF. Characteristics associated with synthetic cannabinoid use among patients treated in a public psychiatric emergency setting. Am J Drug Alcohol Abuse. 2017;43(1):117-122.

49. Lebeau-Craven R, Stein L, Barnett N, et al. Prevalence of alcohol and drug use in an adolescent training facility. Subst Use Misuse. 2003; 38(7):825-834.

50. Sinha R, Easton C. Substance abuse and criminality. J Am Acad Psychiatry Law. 1999;27:513-526.

51. Nurco DN. A long-term program of research on drug use and crime Subst Use Misuse. 1998;33(9):1817-1837.

52. Ögel K, Aksoy A. Tutuklu Ve Hükümlü Ergenlerde Madde Kullanimi. Bağlmlılık Derg. 2007;8:11-17.

53. Algül A, Başar SÜ, Alpay Ateş M, et al. Relationship of substance use disorder to aggression in male subjects with antisocial personality disorder. Düşünen Adam. 2007;20:141-150.

54. Pedersen W, Skardhamar T. Cannabis and crime: findings from a longitudinal study. Addiction. 2010;105(1):109-118. 
55. Yancar C. [Second axis commodities and department of substances dependence and living of personal properties evaluation of quality impact] Madde BağimlilarinI kï nci EkseKomorbi di te Ki şi li Özelli klerïn in BağimliliŞii ddeti Ve YaşaKali tesi Etki si niDeğerlendi ri lmesi; 2005. Available from: http://www.istanbulsaglik.gov.tr/w/ tez/pdf/ruh_sag_hast/dr_cenk_yancar.pdf. Accessed May 8, 2018. Turkish.

56. López-Goñi JJ, Fernández-Montalvo J, Arteaga A, Esarte S. Searching objective criteria for patient assignment in addiction treatment. J Subst Abuse Treat. 2017;76:28-35.

57. Swogger MT, Conner KR, Walsh Z, Maisto SA. Childhood abuse and harmful substance use among criminal offenders. Addict Behav. 2011;36(12):1205-1212.

58. Khoury L, Tang YL, Bradley B, Cubells JF, Ressler KJ. Substance use, childhood traumatic experience, and posttraumatic stress disorder in an urban civilian population. Depress Anxiety. 2010;27(12):1077-1086.

59. Roesler TA, Dafler CE. Chemical dissociation in adults sexually victimized as children: alcohol and drug use in adult survivors. J Subst Abuse Treat. 1993;10(6):537-543.

60. Murray HW, Patkar AA, Mannelli P, DeMaria P, Desai AM, Vergare M. Relationship of aggression, sensation seeking, and impulsivity, with severity of cocaine use. Addict Disord Treat. 2003;2(4):113-121.

61. Hayaki J, Stein MD, Lassor JA, Herman DS, Anderson BJ. Adversity among drug users: relationship to impulsivity. Drug Alcohol Depend. 2005;78(1):65-71.
62. Peters EN, Leeman RF, Fucito LM, et al. Co-occurring marijuana use is associated with medication nonadherence and nonplanning impulsivity in young adult heavy drinkers. Addict Behav. 2012;37(4):420-426.

63. Kirby KN, Petry NM. Heroin and cocaine abusers have higher discount rates for delayed rewards than alcoholics or non-drug-using controls. Addiction . 2004;99(4):461-471.

64. Evren C, Dalbudak E. Relationship of personality trait impulsivity with clinical variables in male alcohol-dependent inpatients. Klin Psikofarmakol Bul. 2009;19:15-23.

65. Chambers RA, Taylor JR, Potenza MN. Developmental neurocircuitry of motivation in adolescence: a critical period of addiction vulnerability. Am J Psychiatry. 2003;160(6):1041-1052.

66. Dougherty DM, Mathias CW, Dawes MA, et al. Impulsivity, attention, memory, and decision-making among adolescent marijuana users. Psychopharmacology. 2013;226(2):307-319.

67. Hammersley R, Forsyth A, Morrison V, Davies JB. The relationship between crime and opioid use. Br J Addict. 1989;84(9):1029-1043.

68. Schneider R, Timko C. Does a history of violence influence treatment, self-help, and 1-year outcomes in substance use disorder patients? J Addict Dis. 2009;28(2):171-179.
Neuropsychiatric Disease and Treatment

\section{Publish your work in this journal}

Neuropsychiatric Disease and Treatment is an international, peerreviewed journal of clinical therapeutics and pharmacology focusing on concise rapid reporting of clinical or pre-clinical studies on a range of neuropsychiatric and neurological disorders. This journal is indexed on PubMed Central, the 'PsycINFO' database and CAS,

\section{Dovepress}

and is the official journal of The International Neuropsychiatric Association (INA). The manuscript management system is completely online and includes a very quick and fair peer-review system, which is all easy to use. Visit http://www.dovepress.com/testimonials.php to read real quotes from published authors. 